\title{
The effect of problem-based learning in patient education after an event of CORONARY heart disease - a randomised study in PRIMARY health care: design and methodology of the COR-PRIM study
}

\author{
Anita Kärner ${ }^{1 *}$, Staffan Nilsson ${ }^{2}$, Tiny Jaarsma ${ }^{1}$, Agneta Andersson³ ${ }^{3}$ Ann-Britt Wiréhn ${ }^{3}$, Peter Wodlin ${ }^{4}$, \\ Lisa Hjelmfors ${ }^{5}$ and Pia Tingström ${ }^{6}$
}

\begin{abstract}
Background: Even though there is convincing evidence that self-care, such as regular exercise and/or stopping smoking, alters the outcomes after an event of coronary heart disease (CHD), risk factors remain. Outcomes can improve if core components of secondary prevention programmes are structurally and pedagogically applied using adult learning principles e.g. problem-based learning (PBL). Until now, most education programs for patients with CHD have not been based on such principles. The basic aim is to discover whether PBL provided in primary health care (PHC) has long-term effects on empowerment and self-care after an event of CHD.
\end{abstract}

Methods/Design: A randomised controlled study is planned for patients with CHD. The primary outcome is empowerment to reach self-care goals. Data collection will be performed at baseline at hospital and after one, three and five years in PHC using quantitative and qualitative methodologies involving questionnaires, medical assessments, interviews, diaries and observations. Randomisation of 165 patients will take place when they are stable in their cardiac condition and have optimised cardiac medication that has not substantially changed during the last month. All patients will receive conventional care from their general practitioner and other care providers. The intervention consists of a patient education program in PHC by trained district nurses (tutors) who will apply PBL to groups of 6-9 patients meeting on 13 occasions for two hours over one year. Patients in the control group will not attend a PBL group but will receive home-sent patient information on 11 occasions during the year.

Discussion: We expect that the 1-year PBL-patient education will improve patients' beliefs, self-efficacy and empowerment to achieve self-care goals significantly more than one year of standardised home-sent patient information. The assumption is that PBL will reduce cardiovascular events in the long-term and will also be cost-effective compared to controls. Further, the knowledge obtained from this study may contribute to improving patients' ability to handle self-care, and furthermore, may reduce the number of patients having subsequent CHD events in Sweden.

Trial registration: NCT01462799

\footnotetext{
* Correspondence: anita.karner@liu.se

'Department of Social and Welfare studies (HAV), Linköping University, Linköping, Sweden

Full list of author information is available at the end of the article
} 


\section{Background}

Despite impressive progress in treatments, coronary heart disease (CHD) is still a major cause of death among men and women in most European countries [1]. In Sweden 41000 individuals suffer a myocardial infarction (MI) every year [2]. About $60 \%$ who survive an MI or related coronary event have a high risk of having another cardiac event [3]. However, these outcomes can be improved by lifestyle changes, e.g. smoking cessation and/or starting regular exercise, as suggested in European guidelines, [4]. Further, medication using e.g. beta -blockers can lead to a $19-48 \%$ decrease in mortality and a $28 \%$ decrease in reinfarction rates [5]. Interestingly, the INTERHEART study [6] showed that nine modifiable factors explain a large (> 90\%) proportion of the threat of developing an initial acute MI. These are smoking, elevated ApoB/ApoA1 ratio, history of hypertension, diabetes, abdominal obesity, psychosocial factors, daily consumption of fruits and vegetables, regular alcohol consumption and regular physical activity [7]. European guidelines emphasise: avoidance of smoking and overweight, physical exercise (at least $30 \mathrm{~min}$ /day), healthy food, blood pressure $<140 / 90 \mathrm{~mm}$ $\mathrm{Hg}$, total cholesterol $<5 \mathrm{mmol} / \mathrm{l}$ [1]. Smoking cessation, intake of fruit and vegetables and exercise can together lower the relative risk of MI by up to $80 \%$ [7]. Although this is known, of more than 4300 asymptomatic patients with CHD, $17 \%$ continue to smoke; $43 \%$ are obese; $70 \%$ have elevated blood pressure, and $66 \%$ have elevated total serum cholesterol about six months after starting medication for hypertension and/or high blood lipids, as analysed retrospectively [8]. To address the effectiveness of multifactorial lifestyle interventions, a study systematically reviewed 25 randomised controlled trials ( $\sim 70700$ patients) in primary and secondary prevention of CHD and type 2 diabetes [9]. The evidence for the interventions was weak overall. The trials were few, samples were small, and the intensity of the interventions was surprisingly low according to the authors predefined minimum level of 60 -min intervention as an inclusion criterion. Thirteen of the 25 studies used low- (11-30 h total) or very low intensity interventions (1-10 h total). The cholesterol levels and blood pressure did not differ between the groups (controls received the usual care). However, body mass index (BMI) was positively affected, as indicated by significantly lower results in lifestyle intervention groups compared to controls. Although the evidence was limited, significant improvements in self-reported risk behaviour were identified regarding at least two of the three key aspects of healthy diet, namely physical activity and stress management. The interventions were considered to have a relevant effect on clinical outcomes such as mortality, cardiac events or hospitalisation. The authors point out the need for further trials to describe interventions transparently regarding, for example, concepts, duration, delivery and adherence. Three levels of information should be included: 1) patient attendance and participation, 2) behavioural change regarding diet, physical exercise and stress management, and 3) clinical/laboratory outcomes. Another recent systematic review [10] of more than 10,000 patients with CHD showed improvements by lifestyle interventions in dietary and exercise outcomes but no overall effect on smoking. However, the authors state that the poor quality of the trials made it difficult to come to concrete conclusions, thus further research is emphasised.

In Sweden, after a CHD event, patients are offered brief cardiac rehabilitation in hospital care, and stable patients are thereafter referred to primary health care (PHC). Self-care goals are, however, not identified or followed-up structurally in PHC, and therefore cannot accurately be supported. Patients' beliefs about CHD and its medication vary qualitatively and may not lead to healthy choices as patients sometimes consider CHD as impossible to affect. For example, they may have fatalistic views, may describe smoking as health promoting, or seldom mention medication as a way of improving the prognosis [11]. Another aspect that affects the accomplishment of self-care goals is linked with hindering or facilitating factors in life [12]. According to Bandura's social cognitive theory of self-regulation, beliefs in one's own capabilities to organize and execute the courses of action required to handle situations in future influence how people think, feel motivated and act [13]. Learning that is based on patients' beliefs is necessary for effective patient education [14,15]. Until now, most education programs for patients with cardiac problems have not included the patients' beliefs and have not been based on adult learning principles including that adults need to know what, how and why they learn. They need to have attention; identify earlier knowledge, and feel motivated to learn. Most pedagogical processes in health care seem to be unplanned and embedded in treatment; the goals are vague or non-existent [16]. However, self-care may improve if structured pedagogical education based on adult learning principles [17] e.g. problem-based learning (PBL), is applied. The basic ideas of PBL are to: have an investigative approach to learning, take responsibility for the learning, use real-life situations, reflect on one's own learning $[18,19]$. PBL can empower patients to improve their self-care [20] by helping them become more active in self-management of their illness, and choosing to change their behaviour [21]. Group education also seems to be of importance. Two Scandinavian systematic reviews of patient education in diabetes management [22], type 2-diabetes and chronic obstructive pulmonary disease (COPD) [23] found that group education led by people with expertise, skilled in the chosen educational model, improved knowledge, empowerment or self-efficacy to manage the disease. The group 
education led to clinically important improvement of long-term glycated haemoglobin $\left(\mathrm{HbA}_{1 \mathrm{c}}\right)$ compared to individual education. In COPD a higher degree of selfmanagement in severe situations due to the disease was found and the education also contributed to fewer COPD-related deaths. According to a Swedish study, joining peer-support groups after CHD resulted in more regular exercise, less smoking, a closer network and more social support compared to those who declined participation in such groups [24]. However, the literature shows inconsistency regarding the benefits of group-based support, which not did change $\mathrm{HbA}_{1 \mathrm{c}}$, cholesterol, blood pressure and well-being at two-year follow-up. The peer supporters showed a decline in well-being at follow-up, implying that this role could be demanding and stressful [25]. This may suggest that peer support is relevant and that group education should be provided by health care personnel skilled in the educational model chosen for the project. Another publication showed that 20 sessions of cognitive behavioural therapy, led by nurses or educational therapists in $\mathrm{PHC}$ and oriented towards educating and motivating the patients, reduced fatal and non-fatal CHD by $41 \%$, and also improved future optimism [26]. Tingström's study using PBL as an educational base after CHD also significantly improved hope for the future and improved patients' knowledge about their illness more, compared to controls, after one year of education [27].

It is a challenge to identify what kind of program is most effective and to what level of intensity it should be provided. The literature and the knowledge of the longterm effects of PBL on self-care after CHD have not been scrutinised or rigorously evaluated, and this constituted the rationale for designing a randomised study. Our basic aim is to discover whether PBL provided in primary health care has long-term effects on empowerment and self-care after an event of coronary heart disease (COR-PRIM). In COR-PRIM, PBL as a foundation for the learning process will be tested against a control group that will be informed by predetermined, written patient information in a structured way based on the traditional model of information transferred to individuals. This will be accomplished to evaluate what type of education is required to affect patient empowerment [21], self-efficacy and beliefs in lifestyle changes [13]. An underlying principle of this project is to identify patients' beliefs about self-care, and to incorporate these as an effective starting point for PBL patient education in PHC.

\section{Study hypothesis}

The hypothesis of the COR-PRIM study is that one year of PBL in patient education improves a patient's beliefs, self-efficacy and empowerment to change selfcare significantly more compared to one year of standardised home-sent patient information.

\section{Methods/Design \\ Study design}

A randomised controlled design will be used in this parallel-group study (see Figure 1) including 165 patients with CHD. Half of the patients will be randomised to an experimental group (PBL) and half to a control group (homesent patient information). The study complies with the Declaration of Helsinki and was approved by The Regional Ethical Review Board in Linköping, Dnr 2010/128-31.

\section{Nurses training}

The selection and training of nurses is fundamental to this project. The goal is to recruit district nurses working in PHC and if possible with experience of patients with CHD. The nurses will be offered the opportunity to take part in a training session for two days given by the project team. The training involves learning about tutoring, with a focus on the central characteristics of PBL e.g. learnercentred, self-directed, real life situations and problemsolving [28]. Starting points that will be used to trigger the patient's problem-solving process will be developed by the nurses in collaboration with the research team. Later on, the nurses will be tutored monthly by the first and last author during the whole process in order to discuss and develop their work. The nurses will also take part in seminars reporting on findings e.g. patients' beliefs about self-care and the enactment of PBL in the groups, throughout the study.

\section{Study population}

\section{Patients and study site}

Eligible patients will be identified at the heart unit, Vrinnevi hospital in Norrkoping, Sweden, from the electronic medical record based on the following criteria. The inclusion criteria in the study are: patients of all ages with CHD verified by $\mathrm{MI}$ and/or Percutaneous Coronary Intervention (PCI) and/or coronary artery bypass surgery (CABG) within 12 months before the planned start of the intervention. Patients should be stable regarding their cardiac conditions and have optimised cardiac medication that has not substantially changed during the last month; they should have completed heart school in hospital care (if applicable); and should be listed at one of six specific PHC centres that have agreed to join the project at the time of inclusion. Exclusion criteria from the study are: planned CABG or other conditions demanding continued cardiologist care; e.g. on-going contact with heart failure clinic due to drug titration or investigations, e.g. myocardial scintigraphy to detect ischemia before a new PCI; life expectancy $\leq$ one year; documented psychiatric disease causing difficulties cooperating with other people; or 


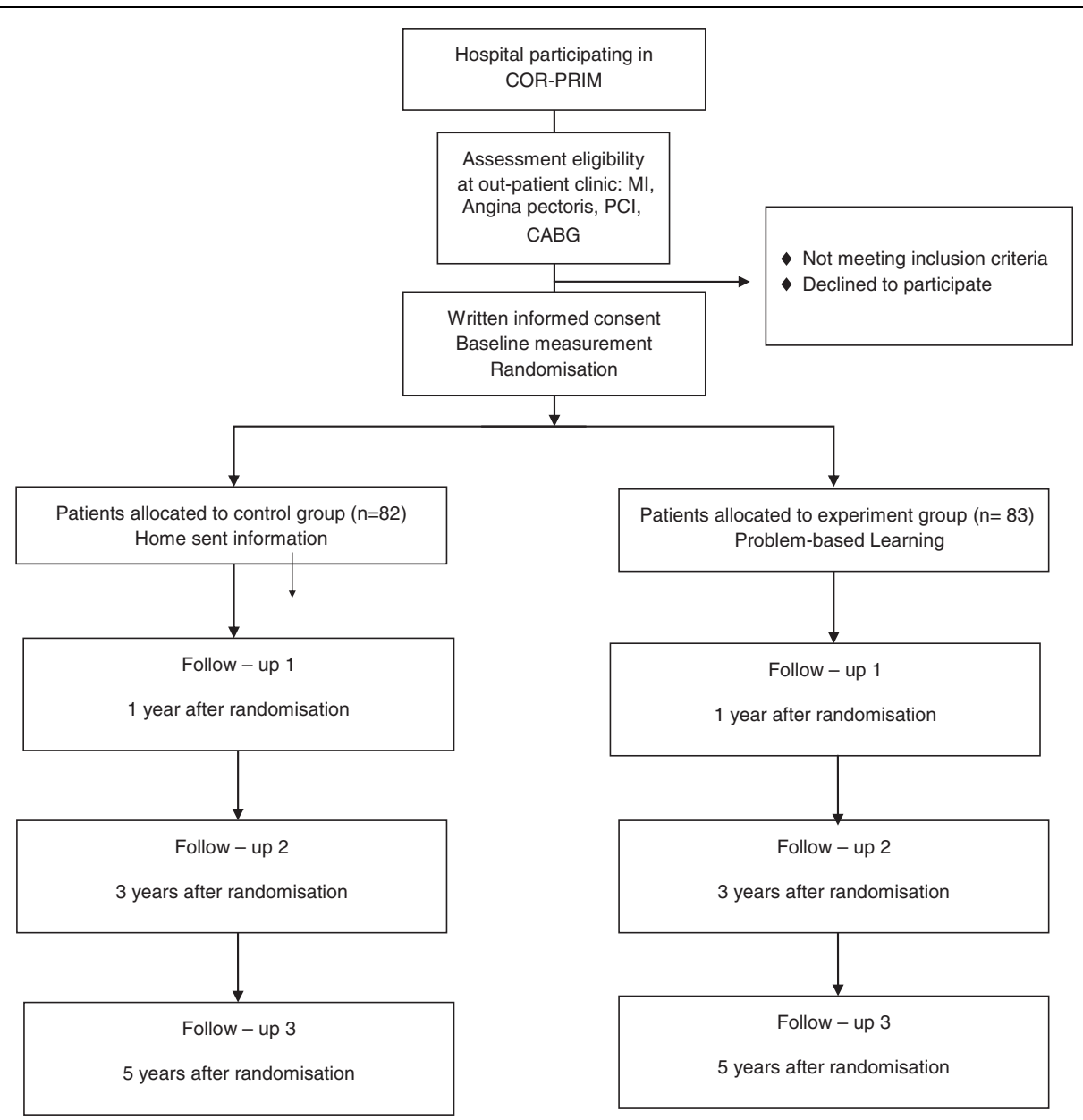

Figure 1 Study design.

obvious abuse of alcohol or narcotics. Patients will also be excluded if they are unable to communicate or read the Swedish language and if they are participating in other studies affecting the results.

\section{Conventional care and interventions Conventional care}

After the hospital care, all patients will be offered individual information about CHD, self-care and treatment. Cardiac rehabilitation will also be accessible at an outpatient clinic at the hospital. This will involve counselling visits with a nurse and a cardiologist about four weeks and 6-12 months after discharge respectively; physical exercise 1-2 times per week, for 3-4 months; and diet counselling. In addition, there is also a heart school for one day, mainly focussing on CHD, physical exercise, stress, diet and medication. If the condition permits, i.e. the patient's symptoms are stable, patients will be referred to PHC. Follow-up will be provided by a general practitioner (GP) if needed due to issues associated with blood pressure, blood lipids and smoking.
Thereafter, follow-up by the GP will be offered yearly in most cases.

\section{Intervention group PBL}

These patients will receive $\mathrm{PBL}$ patient education in PHC to support self-care (see below), and also conventional care as described above.

The overall goal of the education is to improve selfcare through strengthened empowerment

Partial goals are to:

- Understand the health benefits of lifestyle changes that the patients want to accomplish

- Cope with situations challenging accomplishment of lifestyle changes

- Understand and cope with:

- Symptoms (angina pectoris, dyspnoea, swelling legs, tiredness) 
- Changes in diet, physical exercise, medication, psychosocial factors, sexual life

- Mental reactions of CHD (depression, anxiety, fear)

- Working life (vocational training, stress, dynamic and static work)

- Patient education according to the principles of PBL will be provided to a group of 6-9 patients, meeting for a total of 13 occasions for two hours. This will be every week for the first month, then for the next two months there will be two meetings/month and at 16, 20, 26, 39 and 52 weeks after the start. The PBL-intervention will be completed one year after the start.

- A PBL model (Figure 2) [27] supporting the patients learning about self-care will be used. A study guide for the patients will be provided in which learning-and self-care goals may be documented by the patients.

- At each meeting the patients use triggers e.g. pictures, texts or concrete materials as starting points for their learning process

- District nurses work as tutors after completion of a tutorial education. They support the patients in formulating issues, shared learning goals- and individual self-care goals.

- Resource persons, e.g. a physician, physiotherapist, dietician, or social worker, could be invited to respond to questions not solved by the patients themselves. Relatives/family members could also be invited to these meetings.

- During the last meeting, focus-group interviews will be performed to collect data about patients' beliefs, their performance of self-care, and their experiences during the study.

\section{Control group receiving home-sent patient information}

These patients will serve as controls. They will receive conventional care as well as the following patient education to support self-care.
- Patient education about self-care according to predetermined written patient information [29] will be provided to a group of patients consisting of 6-9 people at a meeting in $\mathrm{PHC}$ directly following randomisation and again after one year.

- Events linked to the study during the year will be presented at the first meeting, for example regarding the background and aims of the study, the distribution of patient information, and follow-up measurements.

- Written patient information will be mailed to the patients' homes at the same times as the PBL meetings.

- During the last meeting, focus-group interviews will be performed to collect data about the patients' beliefs, their performance of self-care, and their experiences during the study.

Material used in both groups will include a patient diary to document experiences of self-care, and brochures produced e.g. by The Swedish Heart and Lung Foundation.

\section{Study outcomes and assessment}

To determine whether the pedagogical methodology, called PBL, is practicable for achieving self-care goals in the long-term compared to standardised home-sent patient information, study outcomes on achieving self-care goals of patients with CHD will be performed by analysing and comparing patients' beliefs, self-efficacy, and empowerment to make changes in self-care, considering patients using PBL and those using home-sent patient information. Also, to determine the effects of PBL on reducing new cardiovascular events, smoking, blood pressure, BMI, waist measurement, $\mathrm{HbA1C}$, fp-Glucose, plasma lipids, cost-utility and health care consumption by comparing the outcome in PBL-groups with the outcome in control groups (home-sent patient information). Following verification of appropriateness and informed consent, patients' baseline characteristics will be

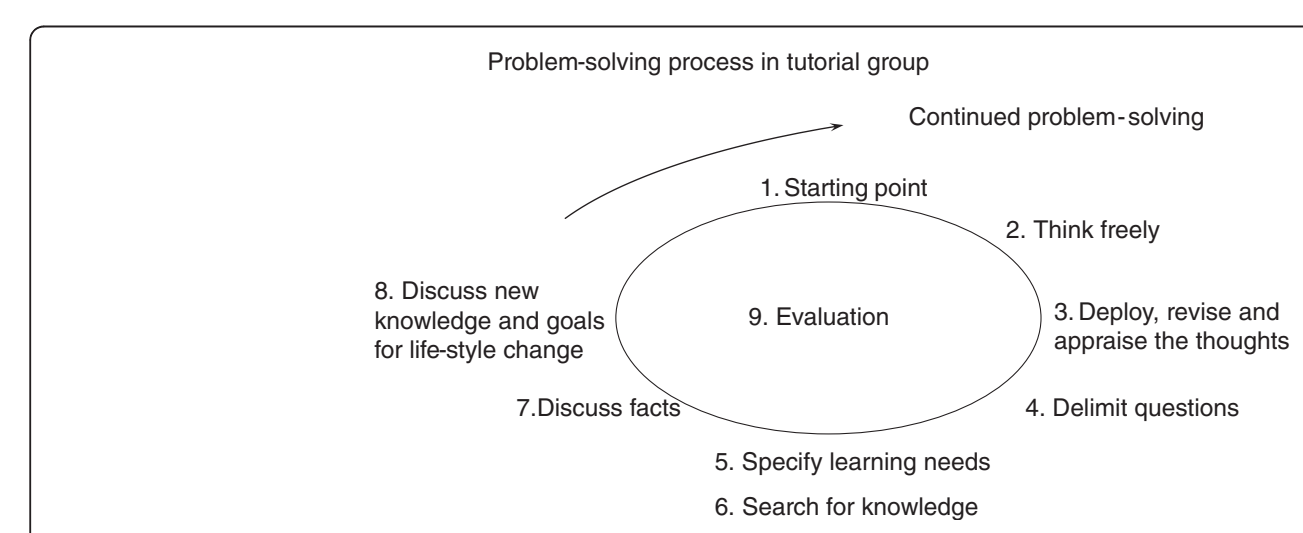

Figure 2 PBL process. 
Table 1 Measurement scheme

\begin{tabular}{|c|c|c|c|c|c|}
\hline Variable & Instrument & Baseline & 1 year & 3 years & 5 years \\
\hline \multicolumn{6}{|l|}{ Primary outcome } \\
\hline a. Empowerment & Swe-CES-10 & $x$ & $x$ & $x$ & $x$ \\
\hline \multicolumn{6}{|l|}{ Secondary outcomes } \\
\hline b. Self-efficacy & GSES, NSES, & $x$ & $x$ & $x$ & $x$ \\
\hline c. Physical exercise & PSES, IPAC, Stages of change scale & $x$ & $x$ & $x$ & $x$ \\
\hline d. Well-being & Ladder of life, EQ5D & $x$ & $x$ & $x$ & $x$ \\
\hline e. Risk factors & $\begin{array}{l}\text { Fp-Cholesterol, fp-HDL, fp-LDL, fp-Triglycerides, HbA1c, } \\
\text { fp-Glucose, blood pressure, smoking, BMl, waist measurement }\end{array}$ & $x$ & $x$ & $x$ & $x$ \\
\hline f. Experiences of self-care & Reflective diary & & $x$ & & \\
\hline g. Beliefs about self-care & Focus group interviews & $x$ & $x$ & & \\
\hline h. Enactment of PBL & Observations, interviews and documents & & $x$ & & \\
\hline \multicolumn{2}{|l|}{ Feasibility of the intervention } & & $x$ & & \\
\hline
\end{tabular}

This table provides an overview of the time schedule of all measurements, and ways to collect data.Questionnaires: Swe-CES-10: The Swedish version of the coronary empowerment scale is a modified version of the Swedish version of the diabetes empowerment scale-23 [31]; GSES: The General Self-Efficacy Scale [32], NSES: Nutrition Self-Efficacy Scale [33], PSES: Physical Self-Efficacy Scale [33], IPAC: International Physical Activity Questionnaire [34]; Stages of change Scale [35,36]; Ladder of life [37,38];Swedish version of EQ5D: EuroQol [43].Qualitative analysis: Experiences of self-care documented in reflective diary and analysed by critical discourse analysis [40]; Beliefs of self-care collected in focus groups [48] and analysed by qualitative content analysis [39]; enactment of PBL collected by different methods and using ethnographic analysis [41,42].

collected from the Swedeheart ${ }^{\circledR}$ register and medical chart, interviews, observations and questionnaires (see Table 1). The questionnaire SWE-CES-10 was developed to survey empowerment in patients with CHD. This questionnaire was originally based on SWE-DES-23, which is a valid and reliable tool to assess empowerment in diabetes and rheumatic disease [30,31]. SWE-DES-23 was tested and shortened to become SWE-DES-SF-10 and found to be valid and reliable in relation to the original version. The items were general in their nature and not disease-specific, and this allowed us to contact the creator who authorized an adaptation by replacing the word 'diabetes' with 'heart disease' in all 10 items. The SWE-CES10 is a self-administered questionnaire. Follow-up assessments will take place one, three and five years after randomisation. Data will be collected in PHC and interviews will be performed at locations chosen by the patients.

Primary and secondary outcome measurements will be assessed at baseline and, at one, three and five years after randomisation.

\section{Primary outcomes}

The primary outcome is empowerment to reach selfcare goals one year after randomisation.

\section{Secondary outcomes}

The secondary outcomes to be measured in this study in order to determine the long-term effect of PBL versus home-sent patient information regarding self-care are: selfefficacy in general [32], healthy diet [33] and physical exercise [34-36]; well-being [37,38]. Changes in patients' beliefs about self-care will be assessed using qualitative content analysis [39]. Patients' experiences of self-care documented in a reflective diary by the patients will be qualitatively analysed by critical discourse analysis [40]. The enactment of PBL as an educational model will be assessed by interviews, participant observations and field notes using ethnographic analysis [41,42]. New cardiovascular events, blood pressure, BMI, waist measurement and blood tests will be followedup to objectively measure effects of self-care. Also, costs will be calculated from a health care perspective. Data on costs will be collected prospectively throughout the study for the PBL strategy as well as for the home-sent information strategy. Cost data will include, for example, personnel costs for staff conducting the programmes for PBLintervention and the home-sent information as well as material costs for each approach (fixed and variable costs). Each activity will be measured in minutes and thereafter priced using relevant unit costs for each item.

For the cost-utility analysis the effect data are qualityadjusted life years (QALYs). The EQ-5D [43] will be used to measure health-related quality of life. We will also use effect data in a cost-effectiveness analysis, using the SWE-CES-10 score as an effect measurement after one year.

Health care consumption will be compared for the PBL-intervention group and the home-sent information group receiving home-sent patient information using data collected by the county council.

\section{Sample size}

The sample size was determined for testing whether the difference in mean values between the randomised groups differed from 0 concerning the values in the 
empowerment instrument, SWE-DES - 23 scale [31]. The mean value in the group randomised to having home-sent patient information was expected to be 3.0 (standard deviation $=1.2$ ), whilst the analogue value for those randomised to receiving PBL-education, was 3.6 (standard deviation $=1.2$ ). At a significance level of $5 \%$ and a power of $80 \%$ this yielded the required sample size in each group of at least 63 . The clinical significance of 0.6 in the main outcome score is based on the estimation of discriminant validity showing that patients with diabetes, who could be compared with patients with CHD in terms of life-long disease, who reported poor self-rated health scored around 3 in several subscales of SWE-DES - 23 scale; corresponding figures for those who reported good self-rated health was around 0.6 above 3 [31]. Losses to follow up and missing values will, if reasonably random or not too extensive, be taken care of by substituting mean or median values of real data that are typical for the sample [44]. We will allow for $10 \%$ attrition due to losses to follow-up, and death.

\section{Study organisation and randomisation}

Nurses at the outpatient clinic at Vrinnevi hospital involved in cardiac rehabilitation will identify eligible patients. The patients will receive information about the study by mail, and then, after about two weeks, will be contacted by a researcher to get personal information about what enrolment in the study could mean. The patients will be given the opportunity to ask the researcher questions about the study.

Patients will be enrolled in the study following baseline assessment and written informed consent. In order to initiate one experiment and one control group, 12-18 patients are needed. Randomisation will be carried out, with sealed unmarked opaque envelopes, which will be assigned to an administrator in a room separate from the research and intervention area. By using a block of 18 study numbers, that will be blindly allocated to either the experiment group (PBL-intervention) or the control group (home-sent patient information) [45]. The envelopes will contain a card with a unique number from 1 to 185. The administrator will be blinded during the randomisation process. The outcome assessors will be blinded during analysis of new cardiovascular events. The patients and nurses/tutors will not be blinded as the patient education as the PBL education obviously differs from the home-sent information.

\section{Analysis}

All analyses will be conducted according to the intention-to-treat- principle. Appropriate quantitative methods for parametric analyses regarding normally distributed, continuous data will be compared by using e.g. Student's $t$ test and non-parametric analysis for data that is not normally distributed will be performed.
The primary variable 'empowerment to reach self-care goals' will be evaluated using non - parametric methods, e.g. a Mann-Whitney U test. P-values below 0.05 will be considered as statistically significant.

The project started in November 2010 with a pilot study to identify the feasibility of the intervention [46]. The result of the pilot study was that it was feasible to organize the study in PHC. Fifty-three per cent $(n=17)$ of eligible patients joined and were randomly allocated according to the design. The pilot study involves a small- scale ethnographic element [47] with the aim of identifying and describing the enactment of PBLprocesses in the experiment group using PBL. The collection of all data in the pilot study (one-year follow-up) was completed in December 2011.

The main study started in September 2011 and the first study patients were included. We are planning to enrol patients during 2011-2014 and follow-up will continue until 2019. The first finding of the COR-PRIM study will become available in 2014, and the first results of the main study around 2015 .

\section{Discussion and conclusion}

Secondary prevention may positively influence risk factors and thus also reduce the number of recurrent coronary events. In the long term, secondary prevention requires co-operation between hospital care and PHC. Not considering the gap between these caring levels impairs the quality of care. Current strategies for secondary prevention do not work optimally since adult learning principles are not used and patients are not involved in their own goal setting. In the proposed study we will test the effect of a group-based adult learning method - that of PBL. This method is expected to reduce the number of secondary cardiovascular events in the long-term and also be cost-effective compared to home-sent patient information. Long-term follow-up is important for finding out how such interventions affect the patients' future health.

\section{Competing interests \\ The authors declare that they have no conflicting interests.}

\section{Authors' contributions}

AK, TJ, SN and PT designed the study. AA designed the health economics part of the study. A-BW is responsible for statistical methods. AK drafted the manuscript and all authors contributed to the final concept. PW has made a substantial contribution to formulating inclusion- and exclusion criteria and assessments. LH contributed the ethnographic part of the pilot study. All authors have read and approved the final manuscript.

\section{Acknowledgements}

We would like to thank Sanna Lindgren, Elisabeth Svensson, Anita Pehrsson Annika Arkevid, Peter Fremred, Elisabeth Landén, Anneli Rudenäs and Melina Appel for making the practical arrangements in this study. This study is funded by the Swedish Heart and Lung Association project number E091/10, the County Council in Ostergotland, Sweden, project number LiO-125151; LiO92281. 


\section{Author details}

'Department of Social and Welfare studies (HAV), Linköping University, Linköping, Sweden. ${ }^{2}$ Vikbolandet Health Care Center, Primary Health Care in eastern Östergötland, County Council of Östergötland, Norrköping, Sweden. ${ }^{3}$ Local Health Care Research and Development Unit, County Council in Östergötland, Linköping University, Linköping, Sweden. ${ }^{4}$ Department of Cardiology, County Council of Östergötland, Linköping University Hospital, Linköping, Sweden. ${ }^{5}$ Faculty of Health Sciences, Linkoping University, Linköping, Sweden. ${ }^{6}$ Department of Medical and Health Sciences (IMH), Linkoping University, Linköping, Sweden.

Received: 19 December 2011 Accepted: 15 November 2012 Published: 20 November 2012

\section{References}

1. Graham I, Atar D, Borch-Johnsen K, Boysen G, Burell G, Cifkova R, Dallongeville J, De Backer G, Ebrahim S, Gjelsvik B, Herrmann-Lingen C, Hoes A, Humphries S, Knapton M, Perk J, Priori S, Pyorala K, Reiner Z, Ruilope L, Sans-Menendez S, Scholte Op Reimer W, Weissberg P, Wood D, Yarnell J, Zamorano J: European guidelines on cardiovascular disease prevention in clinical practice: executive summary. Eur Heart J 2007, 28:2375-2414

2. The National Board of Health and Welfare: Myocardial infarctions 19872007. In Official statistics of Sweden - Statistics - Health and Medical Care. Stockholm; 2009. http://www.socialstyrelsen.se/publikationer2009/2009-12-7.

3. Simpson CR, Buckley BS, McLernon DJ, Sheikh A, Murphy A, Hannaford PC. Five-year Prognosis in an Incident Cohort of People Presenting with Acute Myocardial Infarction. PLOS One 2011, 6(10):e26573.

4. De Backer G: New European guidelines for cardiovascular disease prevention in clinical practice. Clin Chem Lab Med 2009, 47(2):138-142.

5. Everly $M$, Heaton $P$, Cluxton RJ: Beta-blocker underuse in secondary prevention of myocardial infarction. Ann Pharmacother 2004, 38(2):286-293.

6. De Backer G, Ambrosioni E, Borch-Johnsen K, Brotons C, Cifkova R, Dallongeville J, Ebrahim S, Faergeman O, Graham I, Mancia G, Manger Cats V, Orth-Gomér K, Perk J, Pyärälä K, Rodicio J, Sans S, Sansoy V, Sechtem U, Silber $S$, Thomsen T, Wood D: European guidelines on cardiovacsular disease prevention in clinicla practice. Third joint task force of european and other societies on cardiovascular disease prevention in clinical practice (constituted by representatives of eight societies and by invited experts). Atherosclerosis 2004, 173:381-391.

7. Yusuf S, Hawken S, Ounpuu S, Dans T, Avezum A, Lanas F, McQueen M, Budaj A, Pais P, Varigos J, Lisheng L: Effect of potentially modifiable risk factors associated with myocardial infarction in 52 countries (the INTERHEART study): case-control study. Lancet 2004, 364:937-952.

8. Kotseva K, Wood B, De Backer G, De Bacquer D, Pyärälä K, Reiner Z, Keil U: EUROASPIRE III. Management of cardiovascular risk factors in assymptomatic high-risk patients in general practice: Cross-sectional survey in 12 countries. Eur J Cardiovasc Prev Rehabil 2010, 17(5):530-540.

9. Angermayr $L$, Melchart D, Linde K: Multifactorial lifestyle interventions in the primary and secondary prevention of cardiovascular disease and type 2 diabetes mellitus - A systematic review of randomized controlled trials. Ann Behav Med 2010, 40:49-64.

10. Cole JA, Smith SM, Hart N, Cupples ME: Systematic review of the effect of diet and exercise lifestyle interventions in the secondary prevention of coronary heart disease. Cardiol Res Pract 2011:211. doi:10.4061/2011/ 232351. article ID 232351

11. Kärner A: Patients' and spouses' perspectives on coronary heart disease and its treatment. In Medical Diss. Linköping University: Dept of Medicine and Care; 2004.

12. Kärner A, Tingstrom $P$, Abrandt Dahlgren $M$, Bergdahl B: Incentives for lifestyle changes in patients with coronary heart disease. J Adv Nurs 2005, 51(3):261-275.

13. Bandura A: Exercise of personal and collective efficacy in changing societies. In Self-efficacy in changing societies. Edited by Bandura A. Cambridge: Cambridge university press; 1995.

14. Bubela N, Galloway S, McCay E, McKibbon A, Nage L, Proingle D, Ross E, Shamian J: Factors influencing patients' informational needs at time of hospital discharge. Patient Educ Counsel 1990, 16(1):21-28.

15. Fisher R: Patient education and compliance: a pharmacist's perspective. Patient Educ Counsel 1992, 19(3):261-271.
16. Hult $H$, Lindblad Frid M, Lindh Falk A, Thörne K: Pedagogical processes in healthcare: an exploratory study of pedagogic work with patients and next of kin. Educ Heal 2009, 22(3):1-11.

17. Knowles MS, Holton EF, Swanson RA: The Adult Learner. The definitive classic in adult education and human resourse development. 5 editionth edition. Houston, Texas: Gulf Publishing Company; 1998.

18. Biggs J: Teaching for quality at university. Ballmoor Buckingham: Open university press; 2003.

19. Engel C: Not just a method but a way of learning. In The challenge of problem based-learning. Edited by Boud D, Feletti G. London: Kogan Page; 1991.

20. Williams B, Pace A: Problem based learning in chronic disease management: a review of the research. Patient Educ Counsel 2009, 77:14-19.

21. Funnel M, Anderson R: Patient empowerment: a look back, a look ahead. Diabetes Educ 2003, 29(3):454-462.

22. Swedish Council on Technology Assessment in Health Care: Patient Education in Managing Diabetes - A Systematic Review. Stockholm, Sweden: 2009. Report nr: 195, ISBN 978-91-85413-30-0, ISSN 1400-14032009.

23. Danish Centre for Health Technology Assessment NBoH: Patient Education a Health Technology Assessment. Volume 11th edition. Copenhagen: National Board of Health, Monitoring \& Health Technology Assessment; 2009.

24. Hildingh C, Fridlund B: A 3-year follow-up of participation in peer support groups after a cardiac event. Eur J Cardiovasc Nurs 2004, 3:315-320.

25. Smith S, Paul G, Kelly A, Whitford D, O'Shea E, O'Dowd T: Peer support for patients with type 2 diabetes: cluster randomised controlled trial. BMJ 2011, 342(d715):1-8

26. Gulliksson M, Burell G, Vessby B, Lundin L, Toss H, Svärdsudd K: Randomized controlled trial of cognitive behavioral therapy vs standard treatment to prevent recurrent cardiovascular events in patients with coronary heart disease - Secondary prevention in Uppsala primary health care project (SURPRIM). Arch Intern Med 2011 171(2):134-140.

27. Tingstrom P: Problembased learning inte the rehabilitation of patients with coronary artery disease. Faculty of Health Sciences: Linköping University; 2005.

28. Barrow H: Problembased learning in medicine and beyond: a brief overview. In Bringing problem-based learnin to higher education: theory and practice. Edited by Wilerson L, Gijselaers W. San Fransisco: Jossey-Bass Publisher; 1996.

29. Tang T, Funnel M, Brown M, Kurlander J: Self-management support in "real-world" settings: an empowerment-based intervention. Patient Educ Counsel 2010, 79:178-184.

30. Arvidsson S, Bergman S, Arvidsson B, Fridlund B, Tingström P: Psychometric properties of the Swedish rheumatic disease empowerment scale, SWERES-23. Musculoskeletal Care 2012, 10:101-109.

31. Leksell J, Funnel M, Sandberg G, Smide B, Wiklund G, Wikblad K: Psychometric properties of the Swedish diabetes empowerment scale. Scand J Caring Sci 2007, 21:247-252.

32. Koskinen-Hagman M, Schwarzer R, Jerusalem M: Swedish version of the general self-efficacy scale; 1999. http://www.fu-berlin.de/ health/swedish.htm.

33. Swarzer R, Renner B: Health-specific self-efficacy scales; 1999. http://www. RalfSchwarzer.de/: Berlin.

34. IPAQ, International Physical Activity Questionnaire. https://sites.google.com/ site/theipaq/questionnaires.

35. Kamwendo K, Tingström P, Svensson E, Bergdahl B: The effect of problem based learning on stages of change for exercise behaviour in patients with coronary artery disease. Physiother Res Int 2004, 9(1):24-32.

36. Prochaska J, Redding C, Evers K: The transtheoretical model and stages of change. In Health behavior and health education - theory, research and practice. 3rd edition. Edited by Glanz K, Rimer B, Lewis F. San Francisco: Jossey-Bass; 2002:99-120.

37. Andrews F, Withey S: Social indicators of well-being: American's perceptions of life quality. New York: Plenum; 1976.

38. Cantril H: The pattern of human concerns. New Brunswick, NJ: Rutgers University Press; 1965.

39. Graneheim U, Lundman B: Qualitative content analysis in nursing research: concepts, procedures, and measures to acheive trustworthiness. Nurse Educ Today 2004, 24:105-112.

40. Fairclough N: Critical discourse analysis. The critical study of language. London: Longman; 1995.

41. Emerson RM, Fretz Rl, Shaw LL: Writing Ethnographic Fieldnotes. Chicago: The University of Chicago Press; 1995.

42. Lincoln YS, Guba EG: Naturalistic inquiry. Newbury Park: SAGE; 1985. 
43. Burström K: Hälsorelaterad livskvalitet mätt med EQ-5D. Stockholm: Stockholm Läns Landsting; 2002.

44. Polit DF, Beck CT: Nursing Reserch - Principles and Methods. Seventh Editionth edition. London: Lippincott Williams \& Wilkins; 2003.

45. Matts JP, Lachin JM: Properties of permuted - block randomization in clinical trials. Control Clin Trials 1988, 9:327-344.

46. Kärner A, Tingstrom P, Nilsson S, Jaarsma T: COR-PRIM: longitudinal study on PBL in self-care after CVD- preliminary results from a pilot study. Eur J Cardiovasc Nurs 2011, 10(1):S1-S46.

47. Leininger M: Qualitative research methods in nursing. Ohio: Greyden Press; 1988.

48. Morgan D: Focus groups. Annu Rev Sociol 1996, 22:129-152.

doi:10.1186/1471-2296-13-110

Cite this article as: Kärner et al.: The effect of problem-based learning in patient education after an event of CORONARY heart disease - a

randomised study in PRIMARY health care: design and methodology of the COR-PRIM study. BMC Family Practice 2012 13:110.

\section{Submit your next manuscript to BioMed Central and take full advantage of:}

- Convenient online submission

- Thorough peer review

- No space constraints or color figure charges

- Immediate publication on acceptance

- Inclusion in PubMed, CAS, Scopus and Google Scholar

- Research which is freely available for redistribution 